\title{
Introduction: setting the scene
}

\section{Paul Torremans*}

Intellectual property rights were a prominent element in the Uruguay Round of trade negotiations that resulted in the WTO agreement. In terms of intellectual property the TRIPs Agreement, as part of that WTO agreement, set the scene for the developments over the past decade, during which the Chinese economy saw rapid development and with it the growth in importance of intellectual property rights.

Right holders that enter the Chinese economy saw rapid development and with it the growth in importance of intellectual property rights.

Right holders that enter the Chinese markets seek protection for their rights. Chinese manufacturing facilities are more and more often used to produce branded, patented or copyright protected goods, that are then exported and marketed globally. More and more Chinese companies and individuals also seek protection for their own intellectual property by using the international intellectual property system.

Chinese intellectual property laws have therefore developed rapidly over the past decade. There was an obvious need for a more structured and modern intellectual property system in the context of the adoption of the market economy and, in order to join the WTO, China also needed to comply with the standards set in the TRIPs Agreement.

Substantive rights and modern intellectual property laws are, however, only a first step. Once the necessary legislation is in place, and once industry starts using it, enforcement becomes the next big issue. The theory then has to be put into practice. On this point too there have been fascinating developments in China during the last couple of years.

This book offers a variety of perspectives from academics, judges, politicians and practitioners on these developments in the area of intellectual property law in China. These developments are looked at both from a Chinese and from a European point of view.

The foreword was written by the Hon. Dr H.C. Cao Jianming, VicePresident of the Supreme People's Court of the People's Republic of China

* Professor, School of Law, University of Nottingham, UK and Faculty of Law, University of Ghent, Belgium. 
and Grand Justice of the first rank. From his unique position at the top of the Supreme People's Court he looks at these recent developments in Chinese intellectual property law. He looks at substantive law, but mainly at enforcement issues, in an essay entitled 'The Recent Development and Current Status of Judicial Protection of Intellectual Property in China'. He summarized his findings as follows:

Although the Chinese economy has developed rapidly, China will remain a developing country for a long time. Piracy, counterfeiting and other infringements of intellectual property rights are still a serious problem in certain areas. As an important aspect of intellectual property enforcement, the status, function and task of judicial protection of intellectual property rights will become even more important, apparent and difficult with respect to domestic development and intellectual competition. How to realize the fundamental and leading role of judicial protection in the overall protection system is a major topic for all of us. China has successfully established its regime for the protection of intellectual property rights. Although with shortcomings, this regime is working actively and creatively. China's determination to secure the protection of intellectual property rights has never changed. Her attitude towards strict punishment of criminal offences against and infringement of intellectual property rights is clear. China's stand on protecting intellectual property rights in accordance with the law is firm. At the same time, the protection of intellectual property rights is not only the task of administrative authorities and judiciaries. It also requires active participation and cooperation of the owners of intellectual property and the awareness of the general public. We hope that all right holders, including foreign enterprises and individuals, will actively protect their legitimate rights and interest and seek judicial remedies through legal procedures where necessary.

Chinese courts will fulfil even further and with even more determination their function regarding the judicial protection of intellectual property rights. They will equally protect the legitimate interests of both domestic and foreign right holders, increase the degree of protection and try to create a good environment of judicial protection for intellectual property rights, where owners protect their rights actively, courts adjudicate appropriately and fairly, and enforce their rulings effectively, and where infringement is punished without doubt or hesitation.

Part I of the book thus looks both from a Chinese and from a European perspective at issues surrounding the question whether the substantive intellectual property laws are TRIPs compliant.

The Chinese perspective is offered in an essay that was written by Professor Guo Shoukang of the School of Law at Renmin University and by Zuo Xiaodong, who is Director and Legal Counsel at the China Ground Enterprises Group. Professor Guo Shoukang is the éminence grise of Chinese intellectual property and he is therefore ideally placed to paint the picture of the substantive law developments before asking the final question, whether the result is TRIPs compliant. The essay then goes on to consider future developments of the system and the need for it to serve also the specific demands of the developing 
Chinese economy and society. The authors in the end come to the following conclusion:

To sum up, China's intellectual property law offers protection basically consistent with the requirement of TRIPs. It shall be made clear that the existence of infringement of intellectual property rights does not necessarily mean that the intellectual property law or its enforcement has a problem. Attention shall be paid to whether effective remedies have been provided in respect of activities infringing intellectual property rights. China's intellectual property protection regime is being improved; its enforcement is being strengthened. In the process of implementing international treaties, China has demonstrated the credibility of a responsible super nation.

Besides meeting the requirement of TRIPs, China's intellectual property laws also need to be adjusted to the requirement of the development of society and to technological advance. In such a process, certain regulation of China's intellectual property law have exceeded the requirement of TRIPs. For example, in order to meet the need of developing information technology, the right of dissemination through information networks is provided in the 2001 Copyright Law. And the 'Interpretation of the Supreme People's Court on Several Issues concerning the Application of Law in the Trial of Cases in Relation to Copyright Disputes over Computer Network' ${ }^{1}$ was adopted by the Supreme People's Court. The Regulation on the Protection of the Right to Dissemination through Information Network is being drafted at the moment and is presumably going to be promulgated soon. ${ }^{2}$ This will pave the way for China to join the WIPO Copyright Treaty (WCT) and the WIPO Performances and Phonograms Treaty (WPPT). At the moment, a new wave of amendments of China's intellectual property laws is being prepared in order to meet the need of social, economic, technological and cultural development and the challenge of emerging new issues. Alongside the development and advance of the society, economy and technology, the protection of intellectual property in China will be continuously improved and strengthened.

I next offer a European perspective that focuses more heavily on the shortcomings and problems that have been identified in the TRIPs framework over a decade of experience. Through a thorough analysis of the TRIPs provisions concerning substantive patent, trade mark and copyright law, an overall assessment of the fairness and effectiveness of TRIPs is made. This is then coupled with an analysis of the objectives and principles of the agreement and its place in the overall WTO agreement. From this analysis emerges a suggestion that Article 7 TRIPs and its role should be reviewed and enhanced in order to restore the balance.

1 Adopted 22 November 2000, amended 2 January 2004.

2 It is also translated as Regulations on the Protection of the Right of Communication through Information Network. However, it is the view of the translator that the Chinese term '传播' is better represented by the word 'dissemination' than 'communication'. The draft can be found in http://www.chinaiprlaw.com/english/ laws/laws22.htm. (Note by the translator.) 
Part II of the book then shifts the TRIPs compliance emphasis to the issues surrounding enforcement of rights. In order to situate these issues correctly Professor Daniel Gervais of the University of Ottawa sets the ball rolling, looking at the TRIPs Agreement and the changing landscape of international intellectual property. This leads him to the following conclusions:

Without adequate IP protection, economic development will not occur at an optimal level, though it is unclear whether IP rules have any positive effect on the development of the truly poorer nations. In addition, we now know that, while IP is an essential ingredient, it does not, by itself, make an economic plan. Many more elements are required. I argue that, for both practical reasons and on the basis of available empirical data, TRIPS should be seen, and accepted, as a given. Further, it may be defended as an appropriate reference point for developing nations in the context of TRIPS Plus bilateral trade discussions. Indeed, post-TRIPS developments have been going in two (arguably diverging) directions. On the one hand, TRIPS-related development within WTO, as well as recent developments in WIPO, have tried to be more responsive to the perceived needs of developing countries and the interests of users in securing access to protected content and material on terms they consider reasonable. This even includes broad exceptions to obligations to obtain permissions and licences. On the other hand, IP developments in bilateral and regional trade agreements mirror the so-called 'maximalist' approach. This latter trend to regulate IP rights through bilateral regimes may not immediately threaten the balanced approach of WTO and WIPO, but these bilateral initiatives likely will have a significant impact in the long run. TRIPS contains a number of rules that WTO members must implement, but it also affords a fair margin of 'policy flexibility'. Thus, implementing TRIPS may and should be viewed as part of a broader knowledge strategy resting on priority setting, education and institutional capacity-building, regulatory adaptation, FDI 'marketing', and patent mining. Finally, if TRIPS were defended as the 'correct' international norm, it would have the effect of buttressing the position that TRIPS Plus is inadequate at this juncture for many, and perhaps most, developing countries.

Afterwards the emphasis shifts towards enforcement in the strictest sense. Piracy and counterfeiting are still a significant threat for right holders, with which the Chinese enforcement system grapples on a day-to-day basis. One of the unique aspects of that Chinese enforcement system is its administrative component. That administrative enforcement system and its role in the fight against piracy is examined in Chapter 4, by Kristie Thomas of the University of Nottingham in Ningbo. Her analysis leads her to conclude as follows:

It is clear that, despite significant changes in the intellectual property enforcement system in China as a result of WTO accession, enforcement of IP rights through administrative means still dominates. Not only is administrative enforcement chosen by rights holders for its cost-effectiveness, availability and quick resolution, it is also the preferred choice of the state. This official preference for public enforcement mechanisms has been attributed to social and cultural factors such as Confucianism and socialism, leading to a lack of emphasis on individual rights, as well as the role of the legal system in the Chinese economy generally as a tool for policy implementation. 
However, despite the key role of administrative enforcement within the IP framework, there are still various criticisms levelled at the administrative agencies. The most significant criticism is that local protectionism dominates the enforcement of IP at the local level, leading to delays in enforcement and the imposition of insignificant fines. A further observation of the administrative enforcement system is the numerous agencies that compete for dominance within the IP enforcement framework. These bureaucratic rivalries make the implementation of any comprehensive IP strategy virtually impossible, a task already complicated by the perceived gap in authority between central and local governments.

It is undeniable that China's WTO entry and subsequent attempts to comply with the TRIPS Agreement have had a significant effect on the protection of IP in China. The effect of TRIPS has been felt most strongly in the legislative arena, but it has also had a significant effect on the enforcement system. The main change to the administrative enforcement system has been the introduction of judicial review of final administrative decisions, which was previously unavailable. Other changes include the removal of barriers to national treatment within the administrative enforcement system, increases in the maximum fines available for IP infringements, the availability of preliminary injunctions and the lowering of thresholds for criminal liability. It is believed that these changes will have a considerable long-term effect on the IP enforcement system in China, but it is perhaps too soon to see their full impact.

It is clear that administrative enforcement remains an IP holder's main choice for enforcement, but it is also undeniable that the system is beginning to change. With judges gaining more experience of IP disputes and beginning to issue preliminary injunctions more regularly, the civil system will begin to appeal more to rights holders. However, it is unlikely that administrative enforcement will ever be abandoned; it is more likely that it will continue to play an important role in IP enforcement in China, as a fast and cost-effective method to curb infringements as part of a wider strategy of IP protection.

In the foreword we were offered a view from the bench on the issues surrounding enforcement. But the administrative, as well as the judicial (civil and criminal), enforcement system need to be put into practice by the right holders and their lawyers. They look at it from a different perspective and that perspective is offered in Chapter 5, by Jingzhou Tao, of DLA Piper Rudnick Gray Cary UK LLP. His conclusion is a rather critical one. In his words:

The shortcomings in intellectual property rights enforcement in China and the sluggish pace of improvement have invited much criticism from other WTO members, in particular the US, EU members and Japan. In recent years, the US trade delegation has repeatedly visited China and negotiated with the Chinese government with regard to intellectual property rights enticement issues. Faced with great international pressure and the risk of trade wars triggered by the dissatisfaction of the other WTO member countries, the Chinese government's habitual reaction is to launch periodic anti-counterfeiting and anti-piracy campaigns and to issue various specific rules to show to the world that it continues to make progress in its intellectual property rights legislation. Nevertheless, such actions have thus far produced little effect. It may take decades for the Chinese government to thoroughly curb rampant intellectual property rights infringement in China. 
Having dealt with the enforcement of mainstream intellectual property rights in the traditional markets, we return to the bench for an analysis of the protection which the Chinese legal system offers copyright and trademark owners in cyberspace. The Hon. Dr Jiang Zhipei, Justice of the Supreme People's Court of China and Director of the Third Civil Chamber, demonstrates that China has successfully faced up to these advanced and complex issues that surround the use, infringement and enforcement of copyright and trade mark rights on the Internet. He is therefore able to draw the following broad conclusion:

It has been more than four years since China's WTO accession. China's reform and opening up has reached the new era of building a harmonious socialist society. The reform of the Chinese judicial system has also progressed further in order to provide effective legal protection, in order to fulfil the goal of building a harmonious society. The much-noticed 'professionalisation of Chinese judges' has also made continuous and in-depth progress. The judicial protection of intellectual property in China will surely become fairer and more effective. This will not only facilitate the protection of intellectual property in China but also contribute to the international protection of intellectual property.

Part III of the book then moves away from the TRIPs Agreement in a narrow sense. Until now we have also primarily looked at mainstream intellectual property rights such as patents, trade marks and copyright and this focus too changes in Part III. Here we look at confidentiality, non-competition clauses, transfer of technology agreements and traditional knowledge.

Professor John Adams, of Notre Dame University and emeritus professor at the University of Sheffield, starts the discussion on confidentiality and noncompetition in Chapter 7 by offering a European perspective. His analysis highlights the tension between the need to allow employees freedom to practise their trade, wherever they choose to go, and the need for employers to protect their legitimate interests. He concludes by reminding ourselves what an employer's legitimate interests are. Once one accepts that only these interests can be taken into account in the balancing act, a solution becomes a bit more obvious. The emphasis falls here on the protection of the employer's genuine trade secrets; that is, the information has the character that the law recognizes as having the character of a trade secret.

In Chapter 8, this is followed up from a Chinese perspective by Professor Hailing Shan of the School of International Law of East China University of Politics and Law. She focuses on the protection of know-how in Chinese enterprises and in employment relationships:

Protection of trade secrets in China has been through a process of improving from no protection to protection, from a piecemeal approach to consolidated protection, from protection that was narrow in scope to wide protection, from domestic law protection to protection under bilateral agreements, international treaties and global conventions. However, like the protection of other intellectual properties, China still 
has a huge task in establishing a coherent regime of trade secrets protections. This task is particularly difficult because, for historical reasons, the enactment of Chinese laws, including those regarding trade secrets, has been subject to external pressures and a lack of basic infrastructure, which has influenced, to a certain extent, the fairness and effective implementation of the legislation. Therefore, the improvement of the Chinese legal framework on the protection of trade secrets shall be based upon experiences of other jurisdictions, taking into consideration, as the starting point, the reality of the country and the need for further development. It shall aim at establishing a trade secrets protection regime with special characteristics and in accordance with international standards, in order to facilitate the advance in technology and investment and to protect the public interest.

Leaving confidentiality behind, we turn to the protection of traditional knowledge in Chapter 9. Professor Zhu Lanye of East China University of Politics and Law asks in this respect the question whether this is really an efficient way to protect poor countries' intellectual property. She looks at this from an international as well as from a Chinese perspective before concluding:

Compared with the huge amount of traditional knowledge existing today, all work done cannot meet the requirement of protection, not to say adequate and effective protection. As mentioned in the first part of this essay, before the answers to many questions will be found, this topic will be a long-term important task of WIPO. The existing intellectual property system is obviously not suitable to be used directly on traditional knowledge protection. The developing countries should cooperate and find out a better means to protect traditional knowledge.

Transfer of technology is the final issue which we address in Part III of the book. In Chapter 10, Zou Weining, who is a partner in the Jun He Law Office in Beijing, looks at the new Chinese rules concerning contract for the importation of technology. It is clear that this new system for technology importation contracts represents a vast improvement over the old system and that it reflects China's WTO commitments. Parallel importation, however, remains, as in many other countries, a difficult issue.

Part IV of the book looks at the development agenda and the role of intellectual property and reform of the intellectual property system in this context. We have two interesting perspectives to offer: a philosopher's perspective and a politician's perspective.

Professor Sigrid Sterckx, who specializes in ethics at the Department of Philosophy and Moral Science of the University of Ghent, looks in Chapter 11 at the promises and realities of the WTO TRIPs patent regime after the Doha declaration. This analysis leads her to the following conclusions:

Economic research shows that the nature of technology transfer and the utility of intellectual property rights follow a kind of 'technology ladder'. However, in the continuous process of the 'strengthening' of patents, little or no attention is paid to the economic circumstances in poor countries. The fact that the patent system has 
very diverse effects in different industries - and this is also true in industrialised countries - is also ignored. A strongest-possible and long-lasting patent protection is pursued in all countries and all fields of industry - a 'one size fits all' (viz. extra large) approach.

I would not go as far as Jagdish Bhagwati, one of the most prominent economists of our time, who has claimed in the Financial Times that: . . . [Intellectual Property Protection] is not a 'trade' issue; the WTO ought to be about lowering trade barriers and tackling market access problems. The inclusion of IPP has turned the organization into a royalty collection agency. ${ }^{3}$

Intellectual property rights do have trade-related aspects. But this is precisely why scientists, consumers and patients in both industrialised and developing countries should be so worried about the maximalist rights approach that is currently taken in the field of intellectual property. The urgent challenge we are facing today has been summarised in simple words, but very much to the point, in the recent report of the UK Commission on Intellectual Property Rights.

Developed countries should pay more attention to reconciling their commercial self-interest with the need to reduce poverty in developing countries, which is in everyone's interest. Higher IP standards should not be pressed on developing countries without a series and objective assessment of their impact on development and poor people. We need to ensure that the global IP system evolves so that the needs of developing countries are incorporated and, most importantly, so that it contributes to the reduction of poverty in developing countries by stimulating innovation and technology transfer relevant to them, while also making available the products of technology at the most competitive prices possible.

Intellectual property protection is not per se hostile to the interests of developing countries, but the system should be adapted to reflect their innovation and investment needs. To the extent that this is difficult or impossible, alternative models should be developed that promote the needs of developing countries at much lower social costs than the models that are currently in place.

Chapter 12 then offers a politician's perspective on the importance of intellectual property in international trade relations, but also on the need for reform if the system is to serve the needs of all communities around the world. This chapter is the speech which Minister Fientje Moerman, Deputy Minister-President and Flemish Minister for Economics, Business, Science, Innovation and Foreign Trade of the Flemish Regional Government (Flanders, Belgium) delivered in Shanghai on 24 November 2004 at the Shanghai Conference on Intellectual Property Rights (IPR) and WTO Compliance Chinese and European Perspectives.

By way of postscript, Part V of the book and Chapter 13 set out the agenda for the future.

3 Jagdish Bhagwati (2002), 'Patents and the Poor', The Financial Times, 16 September. 